\title{
Antithrombotic and anti-inflammatory activities of leaf methanolic extract of Euphorbia hirta Lin
}

\begin{abstract}
Euphorbia hirta (Euphorbiaceae family) has been claimed as a useful folk medicine to traditional healers for the treatment of fever, pain, diarrhoea, peptic ulcers, vomiting, asthma, bronchitis, inflammation, kidney stones, and menstrual problems and as antivenom. Therefore, the intention of our study was to evaluate the possible antithrombotic and anti-inflammatory activities of methanolic extract of Euphorbia hirta leaves in mice. The in-vitro clot lysis test was performed to investigate the antithrombotic activity of Euphorbia hirta leaf methanolic extract. In addition, xylene-induced ear edema and cotton pellet-induced granuloma formation tests were conducted to evaluate the anti-inflammatory effect of methanolic extract of Euphorbia hirta leaves in mice. Crude methanolic extract was administrated orally at a dose of 200,400 and $800 \mathrm{mg} / \mathrm{kg}$ in mice. Treatment with crude extract of Euphorbia hirta leaves $(100$ and $200 \mathrm{mg} / \mathrm{mL})$ restrained the in-vitro thrombosis process. In this test, MEHL $200 \mathrm{mg} / \mathrm{mL}$ showed the strongest inhibition value $(38.00 \pm 2.52$ $\%$ ) of thrombosis. The treatment with MEHL at a dose of 200,400 and $800 \mathrm{mg} / \mathrm{kg}$ showed a dose-dependent significant inhibition of ear edema in mice, whereas the highest inhibition value was exhibited by MEHL $800 \mathrm{mg} / \mathrm{kg}(58.78 \pm 2.90 \%)$. Moreover, all of the dosages $(200,400$ and $800 \mathrm{mg} / \mathrm{kg}$ ) of MEHL were significantly reduced the granuloma formation in mice as well as decrease the body weight gain. Here, MEHL $800 \mathrm{mg} / \mathrm{kg}$ provided highest inhibition value $(56.80 \pm 3.85 \%)$ of granuloma formation in mice. Furthermore, no sign of toxicity, behavioral changes or mortality was observed upto the dose of $3200 \mathrm{mg} / \mathrm{kg}$ for MEHL or control group. The present investigation explores that methanolic extract of Euphorbia hirta leaves has moderate antithrombotic and significant anti-inflammatory effects. These outcomes strongly support the traditional uses of this plant scientifically, in case of thrombosis and inflammation management.
\end{abstract}

Keywords: Euphorbia hirta, thrombolysis, anti-inflammatory, cotton pellet
Volume 12 Issue 4 - 2019

\author{
Mushiur Rahman SM,' Sohel Rana,' Ariful Islam \\ AFM, ${ }^{2}$ Alok Kumer, ${ }^{3}$ Abu Kayes Hashem, ${ }^{4}$ \\ Habibur Rahman,' Mohaimenul,' Tonmoy \\ Kumar Biswas, ${ }^{3}$ Sayeed Sabbir AA' \\ 'Department of Pharmacy, Jashore University of Science and \\ Technology, Bangladesh \\ ${ }^{2}$ Executive, Product Development, Aristopharma Ltd, Bangladesh \\ ${ }^{3}$ Department of Pharmacy, State University of Bangladesh, \\ Bangladesh \\ ${ }^{4}$ Department of Pharmacy, East West University, Bangladesh
}

Correspondence: Mushiur Rahman SM, Department of Pharmacy, Jashore University of Science and Technology, Jashore-7408, Bangladesh, Tel +880I632533567, Email smushiurjustphar@gmail.com

Received: June 24, 2019 | Published: August 30, 2019

\section{Introduction}

Nature is the root-source of trustworthy remedies and gifted us plenty of beneficial herbs, vegetables, fruits and medicinal plants which are the reliable resource of traditional medicines used to cure illness widely, since the primitive period of time. ${ }^{1}$ Natural medicines based on medicinal plants are a renowned source of bioactive components which are willingly used for the discovery and development of unique therapeutic agents and the effective management of a broad range of ailments. ${ }^{2}$

Current scientific statistics substantiated that cardiovascular diseases along with thrombosis are the most couple leading causes of world population death. ${ }^{3}$ The formation or emergence of thrombus in an artery or vein which is attributed to platelet adhesion and aggregation, blood vessel injury, endogenous and exogenous coagulation system, and the yield of fibrin is acquainted as thrombosis. ${ }^{4}$ Generally, thrombosis is the most complicated multifactorial pathologic process which is triggering numerous diseases including deep vein thrombosis, ischemic myocardial infarction, atherosclerotic plaques, and sudden death. In addition, thrombosis strongly damages the quality of human life and responsible for much morbidity and mortality. ${ }^{5,6}$ The intravascular thrombosis is one of the main reasons for cardiovascular disease and approximately $99 \%$ infractions are caused by embolic or thrombotic events. ${ }^{5}$ Pharmaceutically manufactured antithrombotic armamentarium such as aspirin, streptokinase, warfarin, and clopidogrel reveal some remarkable adverse effects and might explain the vascular relapses. Gastrointestinal bleeding, prolonged bleeding time, internal bleeding, headache, and palpitation are frequently occurring unexpected effects. ${ }^{7}$ For these reasons, it is highly required to exploration of novel bioactive compounds and medicines from medicinal plants with effective and precise mechanisms of action, therapeutically effective, and less toxicity. ${ }^{3}$

It has always been a conundrum for mankind to understanding inflammation literally. It plays a crucial role in the onset and progression of numerous conditions which is elicited by various noxious stimuli such as antigen-antibody interaction, infectious or aggressive agents (pathogens, irritants, or damaged cells), myocardial infarction and physical or thermal injury ${ }^{8,9}$ Inflammation is considered as an unpleasant complex biological condition which mediated by a number of signaling molecules generated by macrophages, leucocytes and mast cells. ${ }^{10}$ The release of arachidonic acid and inflammatory mediators such as prostaglandin, histamine, serotonin, cytokines, and leukotrienes increase the vascular permeability, as well as facilitating the migration of leukocytes to the site of inflammation..$^{11,12}$ There is 
an inter-correlation between inflammation and pain resulting from the release of analgesic mediators. ${ }^{9}$ Commercially available antiinflammatory drugs such as- steroidal, nonsteroidal (NSAID's) and corticosteroids at high dosage or prolonged use can provoke some undesired and serious side or adverse reactions including osteoporosis, aggravation of ulcers, serious infections, ${ }^{13}$ peptic ulceration, epigastric distress and iatrogenic Cushing's syndrome. ${ }^{8}$ In addition, the rising costs of orthodox medicines are difficult to beard by most people of Bangladesh, especially in the rural parts where the greater percentage of the people are poor and merely subsisting. Consequently, development and establishment of non-toxic along with more powerful and cost-effective anti-inflammatory drugs that can promote a reduction in inflammation process is still needed.

Prominent qualitative compounds yield from medicinal plants such as alkaloids, flavonoids, saponins, glycosides, coumarins, and terpenoids could provide an excellent fountainhead to discover and develop new anti-inflammatory drugs. ${ }^{8}$

Euphorbia hirta L. (belongs to Euphorbiaceae family) is a resourceful plant which has a number of tremendous uses as medicine. Endemically this plat is known as dudhani, dudh ghas, baridudhi, dudeli, asthma plant, dudhi and considered as the biggest genus of this family. ${ }^{14,15}$ This is a small annual broad-leaved herbaceous wild plant native to Australia and commonly found in tropical countries, ${ }^{16}$ especially in Bangladesh and India. Usually, it is erect, slenderstemmed, annual hairy plant with number of branches from the base to top which spreading up to $40 \mathrm{~cm}$ in height, though sometimes it can be seen lying down, reddish or purplish in color. Leaves are elliptical, opposite, oblong-lanceolate or simply oblong, acute or subacute, pale beneath, dark green above, $1-2.5 \mathrm{~cm}$ long, with a faintly toothed edge and blotched with darker or purple on the middle or upper surface. ${ }^{14,17}$ The flowers are generally small, about $1-1.5 \mathrm{~cm}$ in diameter, numerous and crowded together in dense cymes. The leaves and stems of $E$. hirta produce a milky-white juice when cut. It is frequently seen growing open waste spaces, banks of watercourses, pathways, roadsides, and grasslands. ${ }^{17,18}$

Notable chemical compounds of E. hirta are flavonoids (quercetin, myricitrin, rhamnose, rutin, quercitrin, quercitol, leucocyanidin, leucocyanidol, pelargonium 3,5-diglucoside, cyanidin 3,5-diglucoside), terpenoids ( $\alpha$-amyrin, $\beta$-amyrin, $\beta$-sitosterol, campesterol, friedelin, taraxerol, cholesterol, and stigmasterol), phenols, essential oil, tannic, ellagic, gallic, maleic and tartaric acid and other compounds. ${ }^{19,15}$

Traditionally, it is a very popular and trustworthy herb amongst practitioners in folk medicine and widely utilized as a palliative to treat various ailments including fever, intestinal parasites, diarrhoea, peptic ulcers, vomiting, amoebic dysentery, itching, asthma, emphysema, bronchitis, coughs, hay fever, laryngeal spasms, colds, wounds, kidney stones, menstrual problems, sterility abscesses and venereal diseases. In addition, the plant has a well-known reputation as an analgesic to treat severe headache, toothache, rheumatism, colic, and pains during pregnancy. To relieve the pain of scorpion stings and snakebites it is used as an effective antidote. This plant is also used by nursing mothers with deficient milk supply. ${ }^{19,20}$ Moreover, the antiinflammatory, analgesic, antipyretic, sedative, anxiolytic, antifertility, anthelmintic, antiplasmodial, antiamoebic, antimalarial, larvicidal properties of $E$. hirta have been reported in the literature. ${ }^{16,17}$

Therefore, based on the need to establish more effective treatments with considerably fewer side-effects and more safety for thrombosis and inflammation to conventional pharmacotherapy and taking into account the therapeutic potential of the Euphorbia hirta. Moreover, herbs are more efficacious, safe, economic, and reliable, less toxic and accessible natural resource of drugs all over the world. So, the present study is designed to investigate the possible antithrombotic and antiinflammatory activities of leaf methanolic extract of Euphorbia hirta plant.

\section{Materials and Methods}

\section{Chemical reagents and drugs}

Streptokinase and Diclofenac sodium were used as reference drug in this study and purchased from Beacon pharmaceutical Ltd., and Square Pharmaceuticals Ltd., Bangladesh, respectively. All chemicals and reagents used in these experiments were obtained from Merck, Germany of analytical grade and highly pure.

\section{Plant collection and identification}

With the aid of a comprehensive literature review, Euphorbia hirta (Euphorbiaceae) was selected for this investigation known as antithrombotic and anti-inflammatory activities. Freshness leaves of this plant were obtained from the green campus of Jashore University of Science \& Technology (located at $23^{\circ} 14^{\prime} 0^{\prime \prime} \mathrm{N}, 89^{\circ} 77^{\prime} 31^{\prime \prime} \mathrm{E}$ ), Jashore, Bangladesh, in September 2018. The plant was botanically identified and authenticated by the experts of the National Herbarium, Bangladesh and the voucher specimen number is DACB- 46543. A sample of dried specimen was archived in the herbarium for future reference.

\section{Extract preparation}

For the current investigation, approximately $300 \mathrm{gm}$. of pulverized leaves were taken. First, the leaf part of the plant was collected and thoroughly washed 3-4 times successively with fresh current water and once with distilled water to remove all adhering substances (dirt, soil, and contaminants). The leaves were air dried at room temperature $\left(25 \pm 2^{\circ} \mathrm{C}\right)$ for about two weeks and finally dried them for 24 hours at $30 \pm 2^{\circ} \mathrm{C}$ by using a laboratory dryer (memmert UN75, Germany) prior to ground. Then all dried leaves were ground into coarse powder and cold extraction method was applied to extract the active components. Pulverized leaves $(300 \mathrm{gm}$.) were macerated with a sufficient amount of analytical graded methanol $(1800 \mathrm{~mL})$ for 10 -12days at room temperature with periodical shaking and stirring. Finally, the whole mixture was primarily filtered through fresh cotton and then through Whatman No.1 filters. After filtration, the greenish solvent was evaporated at reduced temperature (not more than $40^{\circ} \mathrm{C}$ ) to yield concentrated crude extract. The percentage yield of the crude extract was $4.19 \%(\mathrm{w} / \mathrm{w})$. The crude semisolid extract was then preserved in a refrigerator $\left(\right.$ at $\left.4^{\circ} \mathrm{C}\right)$ till further studies.

\section{Experimental animals}

The test animals were procured from the Department of Pharmacy, Jahangirnagar University, Savar, Dhaka, Bangladesh. To run this study, 4-5weeks aged sixty male young Swiss albino mice of body weight 20-27gm. were used. Animals were kept under standardized environmental conditions, maintained $55 \%-65 \%$ relative humidity and exposed to alternative 12:12hours light and dark cycle at an ambient temperature of $26 \pm 2^{\circ} \mathrm{C}$ before initiating these experiments. The animals were housed in plastic (polypropylene) cages with five mice in each cage, proper supplies of nutritional foods and water ad libitum was ensured. All protocols for the animal experiment were 
examined and endorsed by the Institutional Animal Ethical Committee of Jashore University of Science and Technology, Jashore, Bangladesh. Animals were habituated for 8-10days in our laboratory environment prior to experiment. Constant environmental and adequate nutritional conditions were ensured during the period of experiment.

\section{Antithrombotic study}

Collection of human blood: To conduct the in-vitro antithrombotic study, $2 \mathrm{~mL}$ of human blood was collected from each healthy volunteer $(n=3)$ without a history of oral anticoagulant therapy and all donor was completely acquainted about this experiment.

Procedure: The antithrombotic effect of MEHL was evaluated by the method established by Daginawala, ${ }^{21}$ and slightly modified by Kawsar ${ }^{22}$. Briefly, $2 \mathrm{~mL}$ of pre-collected venous blood was distributed into four different previously weighed sterile micro-centrifuge tubes $(0.5 \mathrm{~mL} /$ tube $)$ and incubated at $37^{\circ} \mathrm{C}$ for $45 \mathrm{~min}$. Serum was completely removed after clot formation without disturbing the clotted blood. The colt containing each micro-centrifuge tube was reweighted to calculate the colt weight by the following formula. tube).

Clot weight $=($ Weight of clot containing tube - Weight of empty

Then, $100 \mu \mathrm{L}$ of methanolic extract of both dosages (50 and $100 \mathrm{mg}$ / $\mathrm{mL}$ ) of Euphorbia hirta leaves was added in each tube separately. Here, commercially available streptokinase (lyophilized Altepase vial of $15,00,000$ I.U) was used as the reference drug. Total $5 \mathrm{ml}$ of sterile distilled water was added with streptokinase vial and mixed properly. This suspension was used as a standard from which $100 \mu \mathrm{L}(30,000$ I.U) was used for in vitro thrombolysis. $100 \mu \mathrm{L}$ of distilled water was used as a negative control and added to the negative control tube numbered. All microcentrifuge tubes were again incubated at $37^{\circ} \mathrm{C}$ for $90 \mathrm{~min}$. After completed the second incubation, released fluid was carefully removed from all tubes and further weighed to determine the difference in weight after clot breakdown.

Total of three replicates $(n=3)$ of each sample was used for statistical analysis and values are represented as mean \pm SEM (Standard Error of Mean). The percentage of clot lysis was calculated by the following standard formula.

Clot lysis $(\%)=($ Weight of tube before clot lysis - Weight of tube after clot lysis) x 100

\section{Acute oral toxicity study}

To select the rational administrative dosages that are safe, nontoxic and most effective, the acute oral toxicity study was performed in compliance with OECD-423 guidelines, acute toxic class method. ${ }^{23}$ In total, ten healthy Swiss albino mice were divided into two groups, containing five mice in each group. MEHL was administered orally in the dose range of $3200,1600,800,400,200$ and $100 \mathrm{mg} / \mathrm{kg}$ body weight, randomly. The animals were kept fasting overnight providing only water ad libitum. Subsequent to administration of the extracts, the animals were observed closely for the first $3 \mathrm{~h}$ for any toxic manifestations such as pain, noisy breathing, mortality, diarrhea, convulsion, salivation, weakness, changes in locomotor activity, aggressiveness, discharge from eyes and ears, injury, food or water refusal, coma and death. Subsequent observations were made at regular intervals for $24 \mathrm{~h}$. The animals were observed for a further week. ${ }^{24}$ The methanolic extracts were safe up to a dose of $3200 \mathrm{mg} /$ $\mathrm{kg}$ body weight, so $200 \mathrm{mg} / \mathrm{kg} 400 \mathrm{mg} / \mathrm{kg}$ and $800 \mathrm{mg} / \mathrm{kg}$ were used as moderate dose for the evaluation of anti-inflammatory activities.

\section{Anti-inflammatory study}

Xylene-induced-ear edema test: The acute anti-inflammatory activity of methanolic extract of Euphorbia hirta leaves was evaluated by xylene-induced ear edema in mice. An established method described previously by Dai\& $\mathrm{Liu}^{25}$ was followed here with slightly modified form. Consisting of five mice in each group, twenty-five mice were randomly divided into five groups and had been fasted for $16 \mathrm{~h}$ with water ad libitum. Group I was orally treated with distilled water $(10 \mathrm{~mL} / \mathrm{kg}$ body weight) as negative control. Mice of group II were orally treated with Diclofenac sodium (DS, $100 \mathrm{mg} / \mathrm{kg}$ body weight) and considered as positive control or standard. Test groups (group III and group IV) were orally administered with MEHL at dosages of 200, 400 and $800 \mathrm{mg} / \mathrm{kg}$ body weight. Acute ear edema was induced by topical application of $20 \mu \mathrm{L}$ of xylene on the anterior and posterior surfaces of the right ear lobe of each animal, after one hour from respective treatment. The left ear was untreated and regarded as control. Mice were sacrificed (1hour later of xylene application) by cutting off both ears with the utilization of $5 \mathrm{~mm}$ circular sections. Finally, the cut portion of each ear was seized and weighed accurately. The weight of ear edema was calculated from the difference between the weight of xylene treated ear (right ear) and the weight of untreated ear (left ear). ${ }^{26}$

The percentage inhibition of ear edema promoted by topical xylene application was determined by the following formula.

Inhibition $(\%)=1-\{$ Weight of edema (extract or standard drug)/ Weight of edema (normal control) $\}$ X 100

Cotton pellet-induced granuloma formation: To search for a new anti-inflammatory agent, cotton pellet-induced granuloma formation in mice is used widely as a valid working model of inflammation. To conduct the cotton pellet-induced granuloma formation in mice, the method established by Swingle\&Shideman, ${ }^{27}$ and with slightly modified by Rahman was performed. ${ }^{24}$ Mice were anaesthetized with light chloroform under aseptic condition. Sterile pre-weighted cotton pellets, weighing $(10 \pm 1) \mathrm{mg}$ of each pellet, were implanted subcutaneously, one on each side of the abdominal (axilla region) of the mice. Healthy twenty-five Swiss albino mice were divided and treated orally as mentioned previous experiment, once a day for seven consecutive days. After completed the routine treatment, all mice were anaesthetized again and dissected on the 8th day. Granuloma wetted cotton pellets were removed and dried for $24 \mathrm{~h}$ at 60 with a laboratory dryer (memmert UN75, Germany). Finally, the dry cotton pellet weight was recorded. The net weight of granuloma formation was calculated by the weight difference between the dried cotton pellets and the cotton pellets before insertion.

The percentage inhibition of granuloma formation in mice generated by cotton pellet implantation was calculated by the following formula.

Inhibition $(\%)=1-\{$ Weight of granuloma (extract or standard drug)/ Weight of granuloma (normal control)\} X 100

\section{Statistical analysis}

Experimental data are presented as mean \pm SEM (standard error of mean). For the statistical assessment, comparison between 
experimental and control groups were performed by one-way ANOVA following Dunnett's test $(P<0.05$, vs. control). The SPSS software (version 20; IBM Corporation, New York, USA) and Graph Pad Prism software (version 5; San Diego, California, USA) were used for the analysis and graph generation of all data, respectively. The obtained results are compared with the vehicle control group where the significance is presented at the level of $P<0.05$.

\section{Results}

\section{Effect of MEHL on thrombosis}

The result of in-vitro antithrombotic activity of MEHL is shown in Table 1. The percent inhibition of thrombosis by the MEHL was $31.67 \pm 1.33 \%$, and $38.00 \pm 2.52 \%$ at the dose of 100 and $200 \mathrm{mg} /$ $\mathrm{mL}$, respectively. The percentage $(\%)$ of clot lysis was significant $(\mathrm{P}<0.05)$ when compared with control. The highest thrombolytic

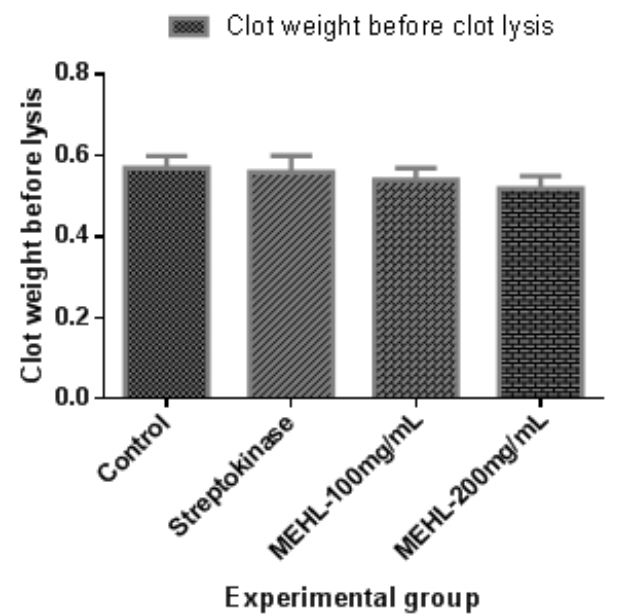

(A) activity generated by MEHL at a dose of $200 \mathrm{mg} / \mathrm{mL}$ showed potent effect of thrombolysis compared to the streptokinase's (standard) clot lysis $(45.33 \pm 2.67 \%)$ activity. On the other hand, distilled water treated as negative control exhibited a negligible percentage of lysis of clot $(3.33 \pm 0.33 \%)$. Result of clot lysis obtained after treating the clots with different dosages of crude extract (MEHL) is illustrated in Figure 1.

\section{Effect of MEHL on acute oral toxicity}

No sign of toxicity, behavioral changes or mortality was observed upto the dose of $3200 \mathrm{mg} / \mathrm{kg}$ for MEHL or control group. During the 14-day observation period, there was no change in food intake or other behaviors and was the same as prior to the experiment. So, the MEHL was safe upto a dose of $3200 \mathrm{mg} / \mathrm{kg}$ body weight. Based on acute oral toxicity results, three different dosages $(200,400$ and $800 \mathrm{mg} / \mathrm{kg})$ were selected for in vivo anti-inflammatory study.

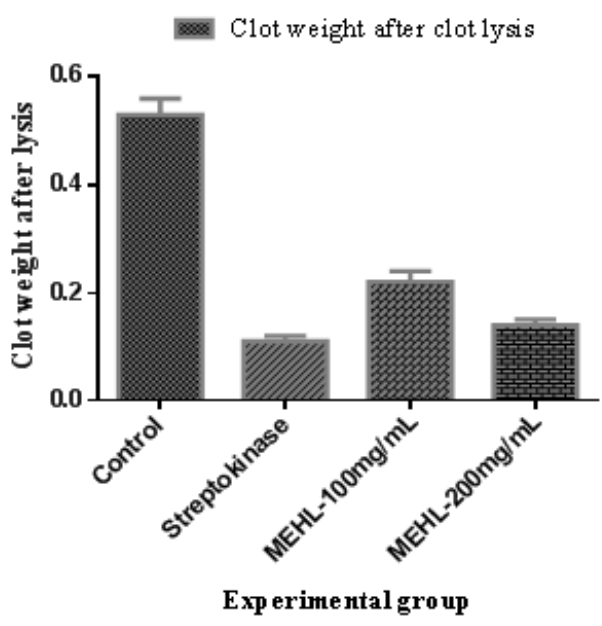

(B)

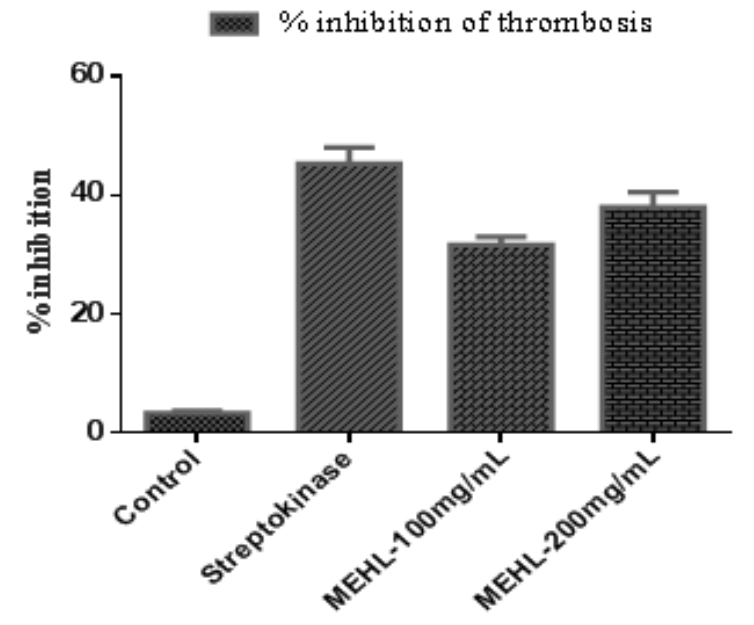

Experimental group

(C)

Figure I Effect of MEHL on thrombosis in in-vitro antithrombotic test.

Effect of methanolic extract of Euphorbia hirta leaves in the treatment on thrombosis. Number of human $(\mathrm{n})=3$. (A) Each bar represents the mean \pm standard error of the mean of clot weight before lysis. (B) Each bar represents the mean \pm standard error of the mean of clot weight after lysis. (C) Each bar represents the percentage (\%) inhibition of thrombosis by respective groups. $p<0.05$ are compared to the values of the negative control group. 
Table I Effect of MEHL on thrombosis in in-vitro antithrombotic test

\begin{tabular}{llcccc}
\hline Group & Dose & $\mathbf{n}$ & $\begin{array}{c}\text { Clot weight } \\
\text { before lysis (gm.) }\end{array}$ & $\begin{array}{c}\text { Clot weight } \\
\text { after lysis (gm.) }\end{array}$ & Inhibition (\%) \\
\hline Control & $100 \mu \mathrm{L}$ & 3 & $0.57 \pm 0.03$ & $0.53 \pm 0.03$ & $3.33 \pm 0.33$ \\
Streptokinase & $100 \mu \mathrm{L}$ & 3 & $0.56 \pm 0.04$ & $0.11 \pm 0.01$ & $45.33 \pm 2.67$ \\
MEHL & $100 \mathrm{mg} / \mathrm{mL}$ & 3 & $0.54 \pm 0.03$ & $0.22 \pm 0.02$ & $31.67 \pm 1.33$ \\
MEHL & $200 \mathrm{mg} / \mathrm{mL}$ & 3 & $0.52 \pm 0.03$ & $0.14 \pm 0.01$ & $38.00 \pm 2.52$ \\
\hline
\end{tabular}

All of the experimental values are presented as mean \pm SEM $(n=3), M E H L=$ Methanol extract of Euphorbia hirta leaves. $p<0.05$ vs. control group $($ Dunnett's test).

\section{Effect of MEHL on xylene-induced ear edema}

The methanolic extract of leaves of Euphorbia hirta reduced the edema in the mice ear induced by xylene. The result of antiinflammatory activity of crude extracts obtained from xylene-induced ear edema in mice is displayed in Table 2. It was observed from results of percentage inhibition of ear edema that all dosages of MEHL have a very significant impact on the reduction of ear edema in mice when compared to the control and was dose-dependent in manner. Among them, $51.06 \pm 6.86 \%$ is the highest value of reduction that was generated by MEHL $800 \mathrm{mg} / \mathrm{kg}$, where the reduction value of standard is $(58.78 \pm 2.90 \%)$. Figure 2 clearly illustrates the observation of xylene-induced ear edema in mice.

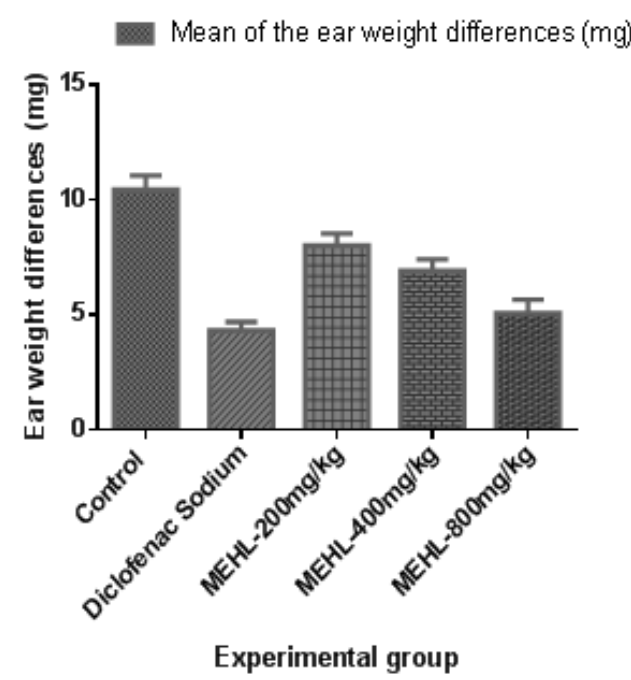

(A)

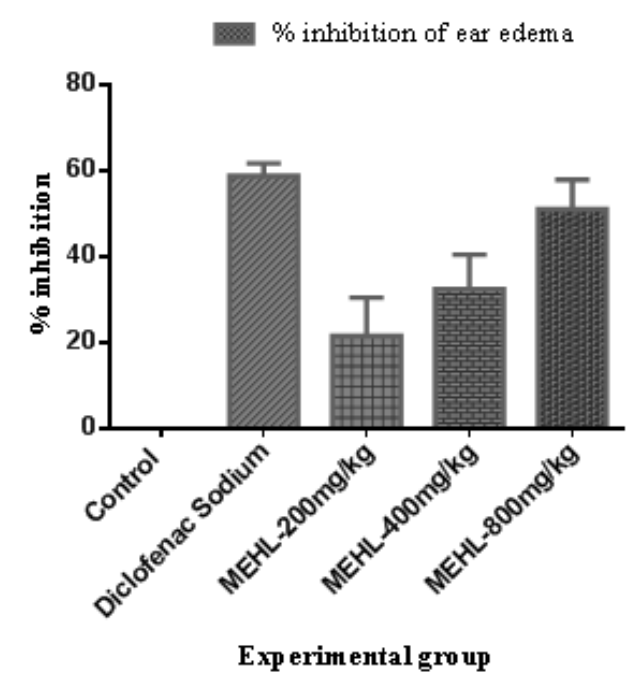

(B)

Figure 2 Effect of MEHL on ear edema in xylene-induced ear edema in mice.

Effect of methanolic extract of Euphorbia hirta leaves treatment on xylene-induced ear edema in mice. Number of animals ( $n$ ) $=5$; Difference between the weight of xylene-treated ear (right ear) and the weight of untreated ear (left ear) was considered to be the edema weight. (A) Each bar represents the mean \pm standard error of the mean of ear edema weight of five animals. (B) Each bar represents the percentage (\%) inhibition of edema formation by respective groups. $p<0.05$ are compared to the values of the negative control group.

Table 2 Effect of MEHL on ear edema in xylene-induced ear edema in mice

\begin{tabular}{lcccc}
\hline Group & Dose & $\mathbf{n}$ & Ear weight differences $(\mathbf{m g})$ & Inhibition (\%) \\
\hline Control & $10 \mathrm{~mL} / \mathrm{kg}$ & 5 & $10.45 \pm 0.6 \mathrm{I}$ & $0.00 \pm 0.00$ \\
$\mathrm{DS}$ & $100 \mathrm{mg} / \mathrm{kg}$ & 5 & $4.30 \pm 0.38$ & $58.78 \pm 2.90$ \\
$\mathrm{MEHL}$ & $200 \mathrm{mg} / \mathrm{kg}$ & 5 & $8.00 \pm 0.53$ & $21.50 \pm 8.95$ \\
$\mathrm{MEHL}$ & $400 \mathrm{mg} / \mathrm{kg}$ & 5 & $6.90 \pm 0.50$ & $32.44 \pm 7.98$ \\
MEHL & $800 \mathrm{mg} / \mathrm{kg}$ & 5 & $5.05 \pm 0.60$ & $51.06 \pm 6.86$ \\
\hline
\end{tabular}

All of the experimental values are presented as mean \pm SEM $(n=5), M E H L=$ Methanol extract of Euphorbia hirta leaves. $p<0.05$ vs. control group $($ Dunnett's test). 


\section{Effect of MEHL on cotton pellet-induced granuloma} formation

The cotton pellet-induced granuloma formation in mice was conducted to determine the therapeutic effect of MEHL to inhibit the chronic inflammation. The result of chronic anti-inflammatory activity of crude extracts obtained from cotton pellet-induced granuloma formation in mice is shown in Tables $3 \& 4$. All of the groups showed

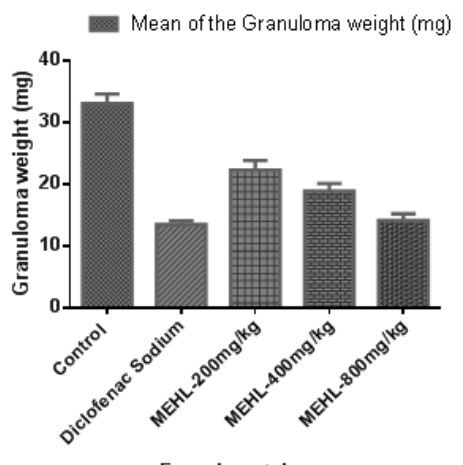

Experimental group a dose-dependent, significant ( $* P<0.05$ versus control) inhibition of granuloma formation in mice when compared to the control. Among them, MEHL at dose of $800 \mathrm{mg} / \mathrm{kg}$ provided highest inhibition value $(56.80 \pm 3.85 \%)$ of granuloma formation in mice, where the inhibition value of standard is $(58.69 \pm 3.32 \%)$. In addition, MEHL extract as well as diclofenac sodium significantly decreased the body weight gain of animals. Figures $3 \& 4$ clearly illustrates both observations of cotton pellet-induced granuloma formation in mice.

Figure 3 Effect of MEHL on granuloma formation in cotton pellet-induced granuloma formation in mice.

Effect of methanolic extract of Euphorbia hirta leaves treatment on dry granuloma weight after subcutaneous cotton-pellet implantation. Number of animals $(n)=5$; Difference between initial weight $(10 \pm 1 \mathrm{mg})$ and weight after overnight drying was considered to be the dry weight of the granuloma tissue. (A) Each bar represents the mean \pm standard error of the mean of granuloma weight of five animals. (B) Each bar represents the percentage (\%) inhibition of granuloma formation by respective groups. $p<0.05$ are compared to the values of the negative control group.

Mean of the body weight at $1^{\text {st }}$ day

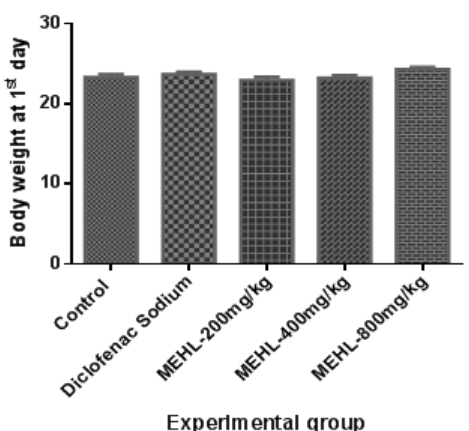

(A)

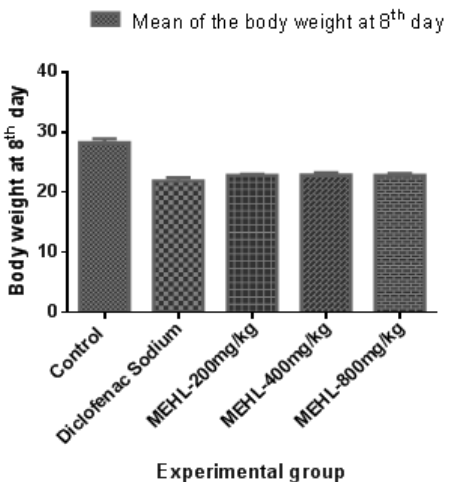

(C)

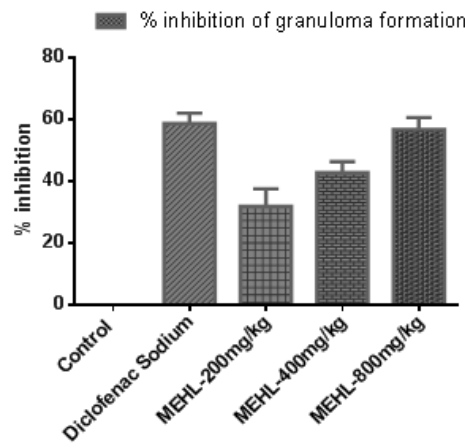

Experimental group

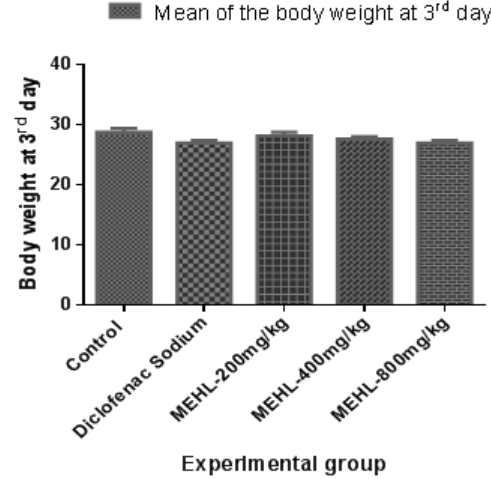

(B)

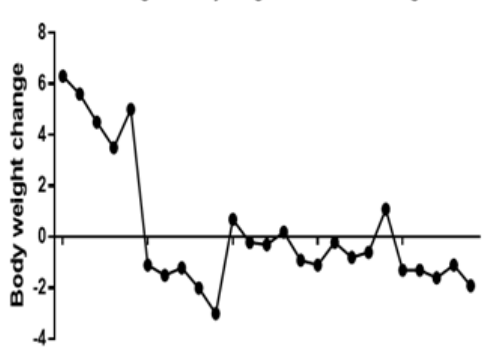

Control Standard $200 \mathrm{mg} / \mathrm{kg} 400 \mathrm{mg} / \mathrm{kg} 800 \mathrm{mg} / \mathrm{kg}$

(D)

Figure 4 Effect of MEHL on body weight in cotton pellet-induced granuloma formation in mice.

Effect of methanolic extract of Euphorbia hirta leaves treatment on body weight changes after subcutaneous cotton-pellet implantation. Number of animals $(n)=$ 5. (A) Each bar represents the mean \pm standard error of the mean of body weight of five animals at $\left.\right|^{\text {st }}$ day. (B) Each bar represents the mean \pm standard error of the mean of body weight of five animals at $3^{\text {rd }}$ day. (C) Each bar represents the mean \pm standard error of the mean of body weight of five animals at $8^{\text {th }}$ day. (D) Represents the body weight change from the normal weight. 
Table 3 Effect of MEHL on granuloma formation in cotton pellet-induced granuloma formation in mice

\begin{tabular}{llccc}
\hline Group & Dose & $\mathbf{n}$ & Granuloma weight $(\mathbf{m g})$ & Inhibition (\%) \\
\hline Control & $10 \mathrm{~mL} / \mathrm{kg}$ & 5 & $33.05 \pm 1.52$ & $0.00 \pm 0.00$ \\
DS & $100 \mathrm{mg} / \mathrm{kg}$ & 5 & $13.47 \pm 0.57$ & $58.69 \pm 3.32$ \\
MEHL & $200 \mathrm{mg} / \mathrm{kg}$ & 5 & $22.30 \pm 1.51$ & $31.84 \pm 5.69$ \\
MEHL & $400 \mathrm{mg} / \mathrm{kg}$ & 5 & $18.88 \pm 1.24$ & $42.71 \pm 3.56$ \\
MEHL & $800 \mathrm{mg} / \mathrm{kg}$ & 5 & $14.13 \pm 1.08$ & $56.80 \pm 3.85$ \\
\hline
\end{tabular}

All of the experimental values are presented as mean \pm SEM $(n=5), M E H L=$ Methanol extract of Euphorbia hirta leaves. $p<0.05$ vs. control group $($ Dunnett's test).

Table 4 Effect of MEHL on body weight in cotton pellet-induced granuloma formation in mice

\begin{tabular}{|c|c|c|c|c|}
\hline Group & Dose & $\begin{array}{l}\text { Weight at I st day } \\
\text { (gm.) }\end{array}$ & $\begin{array}{l}\text { Weight at } 3^{\text {rd }} \text { day } \\
\text { (gm.) }\end{array}$ & $\begin{array}{l}\text { Weight at } 8^{\text {th }} \text { day } \\
\quad \text { (gm.) }\end{array}$ \\
\hline Control & $10 \mathrm{~mL} / \mathrm{kg}$ & $23.30 \pm 0.34$ & $28.70 \pm 0.67$ & $28.28 \pm 0.65$ \\
\hline DS & $100 \mathrm{mg} / \mathrm{kg}$ & $23.64 \pm 0.27$ & $26.94 \pm 0.44$ & $21.88 \pm 0.55$ \\
\hline MEHL & $200 \mathrm{mg} / \mathrm{kg}$ & $22.92 \pm 0.39$ & $28.10 \pm 0.64$ & $22.82 \pm 0.21$ \\
\hline MEHL & $400 \mathrm{mg} / \mathrm{kg}$ & $23.18 \pm 0.33$ & $27.62 \pm 0.37$ & $22.86 \pm 0.34$ \\
\hline MEHL & $800 \mathrm{mg} / \mathrm{kg}$ & $24.26 \pm 0.30$ & $26.96 \pm 0.39$ & $22.82 \pm 0.31$ \\
\hline
\end{tabular}

All of the experimental values are presented as mean \pm SEM $(n=5), M E H L=$ Methanol extract of Euphorbia hirta leaves.

\section{Discussion}

As a significant reservoir of natural remedies, plant-derived medicines have a trustworthy long history of use for the preclusion and treatment of human diseases and potentially helpful for the discovery and development of fancy compounds leading to drugs. ${ }^{2,28}$ The results of our study clearly demonstrate that MEHL significantly represents in vitro thrombolytic and in vivo anti-inflammatory activities though these therapeutic responses were statistically lower than reference drugs.

Pharmacologically, the acute oral toxicity study in mice is a crucial factor in case of search the therapeutic index of medicines and xenobiotics and to select the rational administrative dosages that are safe, non-toxic and most effective for patients. ${ }^{29} \mathrm{Up}$ to the dose as high as $3200 \mathrm{mg} / \mathrm{kg}$ in experimental condition no mortality was observed and thus $\mathrm{LD}_{50}$ of Euphorbia hirta leaves extract could not be obtained. The crude extract was found to be safe and non-toxic with a broad therapeutic range and three comparatively high doses $(200 \mathrm{mg} / \mathrm{kg}$ $400 \mathrm{mg} / \mathrm{kg}$ and $800 \mathrm{mg} / \mathrm{kg}$ ) were used for in-vivo doses.

Nevertheless the comprehensive knowledge acquired so far about antithrombotic activity of Euphorbia hirta leaf extract, this is the first time an antithrombotic effect of Euphorbia hirta leaf extract is determined in vitro. By activating the enzyme plasminogen and converting into plasmin most thrombolytic agents exert their therapeutic effect, which degrades many blood plasma proteins, including fibrin clots. ${ }^{30,31}$ It is evidenced that cell surface-bound bacterial plasminogen is easily converted into the active form plasmin, which could lead to fibrinolysis. ${ }^{30}$ Therefore, lysis of clots is essential for the management of clot-related disorders, including myocardial infarction (heart attack), thromboembolic strokes, arterial thromboembolism, deep vein thrombosis, and pulmonary embolism, to clear a blocked artery that prevents permanent damage to the respective tissues. ${ }^{32}$ Streptokinase (SK), a potent plasminogen activator is secreted from the several species of streptococci and works as cofactor molecule that binds with both plasminogen and fibrinogen. Streptokinase activates plasminogen to lysis fibrin clots and also destroys the extracellular matrix and fibrin fibers that hold cells together despite the presence of the major physiological plasmin inhibitor, $\alpha 2$-antiplasmin. ${ }^{33}$ Streptokinase has been used to treat acute myocardial infarction in developing countries, though plasminogen activator is widely used to manage the disease in developed countries. ${ }^{34}$ In this assay, Euphorbia hirta leaf methanolic extract at both dosages $(100 \& 200 \mathrm{mg} / \mathrm{mL})$ exhibits the moderate antithrombotic activity. Here, MEHL $200 \mathrm{mg} / \mathrm{mL}$ elicited relatively maximum clot dissolution properties and the percentage inhibition is $(38.00 \pm 2.52)$, whereas, reference drug streptokinase exhibits $(45.33 \pm 2.67 \%)$ inhibition. The augmentation in cot lysis by MEHL compared to the negative controls portrays its significant thrombolytic activity and scientifically supports its potential use in clot-related disorders.

In this study, two tests were employed for evaluating the antiinflammatory activity of methanolic leaf extract of Euphorbia hirta, i.e., xylene-induced ear edema and cotton pellet-induced granuloma formation. Xylene, the inflammatory agent was applied to estimate the probable anti-inflammatory effectiveness of the plant extract under study. Xylene-induced ear edema model is one of the most workable and extensively used procedures to elucidate the possible topical antiinflammatory activity of a drug and its probable action mechanism, in case of acute phase of inflammation. ${ }^{35}$ In acute phase of inflammation, in order to provoke vasodilatation and vascular permeability as well as edema four key inflammatory mediators, namely histamine, serotonin, bradykinin, and prostaglandin $(\mathrm{PG})$ are released. ${ }^{35,36}$ On the other hand, xylene-induced ear swelling is accompanied by innate immunity response of the skin, a cytotoxicity reaction of activated $\mathrm{T}$ cells and then migration of PMN leucocytes which augment swelling 
and heaviness of the ear. ${ }^{37}$ Pharmacologically, the inhibition of fluid accumulation generated by topical use of xylene at the treatment site is considered as anti-inflammatory activity. ${ }^{38}$ The methanolic extract of Euphorbia hirta leaves significantly inhibited the ear edema formation in mice induced by xylene due to hindrance of phospholipase A2, which is the precursor of all inflammatory activity. ${ }^{35}$ Respective plant extract shows their antiedematous effect by significantly reduced ear swelling in mice. This result suggested that MEHL (200, 400 and $800 \mathrm{mg} / \mathrm{kg}$, orally) possessed anti-inflammatory activity by inhibition of fluid accumulation through blocking the inflammatory mediators of the acute phase of inflammation. Here, MEHL $800 \mathrm{mg} / \mathrm{kg}$ elicited the strongest anti-inflammatory effect $(51.06 \pm 6.86 \%)$ against xyleneinduced topical acute inflammation, whereas, the standard drug showed $(58.78 \pm 2.90 \%)$ percentage of inhibition. So, further scientific study is required to elucidate the exact mechanism by which the plant extract inhibited ear swelling.

In case of chronic phase of inflammation, the cotton pelletinduced granuloma model has been widely used to screen the possible anti-inflammatory activity of a compound and its probable action mechanism..$^{39}$ It is well known that the synthesis and release of inflammatory cells including neutrophils, macrophages, and fibroblasts are responsible for granuloma formation in the cotton pellet-induced granuloma model. ${ }^{27}$ In addition, the host inflammatory response and the modulation of release of inflammatory mediators are triggered by subcutaneously implanted material (cotton pellet), which finally lead to tissue proliferation and produces granuloma in mice. ${ }^{40}$ Transudative, exudative, and proliferative are the three response phases of the subcutaneous implantation of cotton pellet in mice. Leakage of fluid from blood vessels triggered by increasing in vascular permeability is regarded as transudative phase, the first phase of response. The leakage of protein from bloodstream around granuloma triggered by the intensive maintenance in vascular permeability change is called the exudative phase, the second or intermediate phase of response. Proliferative phase is the third or final phase and defined as the generation of granulomatous tissues caused by continuous release of pro-inflammatory mediators..$^{27,4}$ Strong inhibition in granuloma formation is exerted by steroidal antiinflammatory drugs on both the transudative and proliferative phases of inflammation, whereas diclofenac sodium, one of the NSAIDs drug, provide inhibitory activity only in the final or third phase (proliferative) of inflammation, by inhibiting the cyclooxygenase accompanied with prostaglandin synthesis..$^{27}$ In this study, the methanol extract of Euphorbia hirta leaves decreased the dry weight of the cotton pellets compared to control groups. The experimental groups treated with plant extract (MEHL 200, 400 and $800 \mathrm{mg} / \mathrm{kg}$, orally) elicited a noticeable inhibition on granuloma formation as well as significantly decreased the body weight gain. Among three dosages, MEHL $800 \mathrm{mg} / \mathrm{kg}$ showed the highest percentage inhibition (56.80 \pm 3.85$)$ of granuloma formation in mice and approximately closed to the standard (58.69 \pm 3.32$)$ group.

Therefore, the existence of flavonoids, tannins, triterpenoids and glycosides in MEHL ${ }^{19}$ may be responsible for their significant anti-inflammatory effect ${ }^{8}$ that was observed in both experiments. But further scientific study is needed to identify the specific active compounds and confirm the potential mechanism by which the plant extracts reduced inflammation.

\section{Conclusion}

Our experimental documents are in agreement with previous claims and demonstrate that methanolic extract of Euphorbia hirta leaves possesses the rich amount of anti-inflammatory properties, as shown by the inhibition of ear edema and granuloma formation in mice. Moreover, it could be effective interference in the thrombosis process. These outcomes strongly support the traditional uses of this plant scientifically, in case of thrombosis and inflammation management. However, further quantitative chemical investigation is needed to isolate and elucidate the structure of the active constituents involved in the thrombolytic and anti-inflammatory activities.

\section{Acknowledgements}

The authors are much grateful to the Department of Pharmacy, Jashore University of Science \& Technology, Jashore, Bangladesh for providing facilities to carry out the research work smoothly.

\section{Funding statement}

This arduous research work did not have any particular funding. The total cost of completing the research work was carried by authors own finance.

\section{Ethics approval}

Authors hereby declare that "Principles of laboratory animal care" (NIH publication No. 85-23, revised 1985) were properly followed. All experimental design of this study were examined and approved by ethical research committee of Jashore University of Science and Technology, Jashore- 7408, Bangladesh.

\section{Conflicts of interests}

Authors declared no conflicts of interest.

\section{References}

1. Al-Daihan S, Al-Faham M, Al-shawi N, et al. Antibacterial activity and phytochemical screening of some medicinal plants commonly used in Saudi Arabia against selected pathogenic microorganisms. Journal of King Saud University-Science. 2013;25:115-120.

2. Nesa ML, Karim SMS, Api K, et al. Screening of Baccaurea ramiflora (Lour.) extracts for cytotoxic, analgesic, anti-inflammatory, neuropharmacological and antidiarrheal activities. BMC Complement Altern Med. 2018;18(1):35.

3. Lee W, Lee J, Kulkarni R, et al. Antithrombotic and antiplatelet activities of small-molecule alkaloids from Scolopendra subspinipes mutilans. Sci Rep. 2016;6:21956.

4. Liu X, Wang C, Ding X, et al. A novel selective inhibitor to thrombininduced platelet aggregation purified from the leech Whitmania pigra. Biochem Biophys Res Commun. 2016;473(1):349-354.

5. Arslan R, Bor Z, Bektas N, et al. Antithrombotic effects of ethanol extract of Crataegus orientalis in the carrageenan-induced mice tail thrombosis model. Thromb Res. 2011;127(3):210-213.

6. Cui L, Xing M, Xu L, et al. Antithrombotic components of Malus halliana Koehne flowers. Food Chem Toxicol. 2018;119:326-333.

7. Kim JH, Lee J, Kang S, et al. Antiplatelet and antithrombotic effects of the extract of Lindera obtusiloba leaves. Biomol Ther (Seoul). 2016;24(6):659-664. 
8. Meshram GG, Kumar A, Rizvi W, et al. Evaluation of the antiinflammatory activity of the aqueous and ethanolic extracts of the leaves of Albizzia lebbeck in rats. J Tradit Complement Med. 2015;6(2):172-175.

9. Osadebe PO, Okoye FB. Anti-inflammatory effects of crude methanolic extract and fractions of Alchornea cordifolia leaves. J Ethnopharmacol. 2003;89(1):19-24.

10. Babu NP, Pandikumar P, Ignacimuthu S. Anti-inflammatory activity of Albizia lebbeck Benth, an ethnomedicinal plant, in acute and chronic animal models of inflammation. J Ethnopharmacol. 2009;125(2):356360 .

11. Sarkhel S. Evaluation of the anti-inflammatory activities of Quillaja saponaria Mol. saponin extract in mice. Toxicol Rep. 2015;3:1-3.

12. Yasmen N, Aziz MA, Tajmim A, et al. Analgesic and anti-inflammatory activities of diethyl ether and $\mathrm{n}$-hexane extract of polyalthia suberosa leaves. Evid Based Complement Alternat Med. 2018;2018:5617234.

13. da Silva AO, Damaceno Alves A, Almeida DA, et al. Evaluation of anti-inflammatory and mechanism of action of extract of Macrosiphonia longiflora (Desf.) Müll. Arg. J Ethnopharmacol. 2014;154(2):319-329.

14. Kumar S, Malhotra R, Kumar D. Euphorbia hirta: Its chemistry, traditional and medicinal uses, and pharmacological activities. Pharmacogn Rev. 2010;4(7):58-61.

15. Rahman SM, Rana S, Islam MN, et al. Evaluation of Anxiolytic and Sedative-Like Activities of Methanolic Extract of Euphorbia hirta Leaves in Mice. Pharmacology \& Pharmacy. 2019;10:283-297.

16. Lanhers MC, Fleurentin J, Dorfman P, et al. Analgesic, antipyretic and anti-inflammatory properties of Euphorbia hirta. Planta Med. 1991;57(3):225-231.

17. Rajeh MA, Zuraini Z, Sasidharan S, et al. Assessment of Euphorbia hirta L. leaf, flower, stem and root extracts for their antibacterial and antifungal activity and brine shrimp lethality. Molecules. 2010;15(9):6008-6018.

18. Sandeep BP, Nilofar SN, Chandrakant SM. Review on Phytochemistry and Pharmacological Aspects of Euphorbia hirta Linn. J Pharma Res Health Care. 2009;1(1):113-133.

19. Huang L, Chen S, Yang M. Euphorbia hirta (Feiyangcao): a review on its ethnopharmacology, phytochemistry and pharmacology. Journal of Medicinal Plants Research. 2012;6(39):5176-5185.

20. Basma AA, Zakaria Z, Latha LY, et al. Antioxidant activity and phytochemical screening of the methanol extracts of Euphorbia hirta L. Asian Pac J Trop Med. 2011;4(5):386-390.

21. Prasad S, Kashyap RS, Deopujari JY, et al. Development of an in vitro model to study clot lysis activity of thrombolytic drugs. Thromb J. $12 ; 4: 14$.

22. Kawsar MH, Sikder MA, Rana MS, et al. Studies of thrombolytic, antioxidant and cytotoxic properties of two asteraceous plants of Bangladesh. Bangladesh Pharmaceutical Journal. 2011;14(2):103-106.

23. Ecobichon DJ. The basis of toxicity testing. USA: CRC press; 1997.

24. Rahman SM, Atikullah M, Islam $\mathrm{MN}$, et al. Anti-inflammatory, antinociceptive and antidiarrhoeal activities of methanol and ethyl acetate extract of Hemigraphis alternata leaves in mice. Clinical Phytoscience. 2019;5:16

25. Dai Y, Liu LH, Kou JP. Anti-inflammatory effect of aqueous extract of Wu-Hu-Tang. Journal of China Pharmaceutical University, 1995;6:62364 .
26. Rahman SM, Haque MR, Zaman MA, et al. Evaluation of Methanolic Extract Induced Antinociceptive, Anti-pyretic and Anti-inflammatory Activity of Ficus hispida Leaves. Journal of Pharmaceutical Research International. 2018;8:1-2.

27. Swingle KF, Shideman FE. Phases of the inflammatory response to subcutaneous implantation of a cotton pellet and their modification by certain antiinflammatory agents. J Pharmacol Exp Ther. 1972;183(1):226234.

28. Rahman MA, Sultana R, Bin Emran T, et al. Effect of organic extracts on six Bangladeshi plants on in vitro thrombolysis and cytotoxicity. BMC Complement Altern Med. 2013;13:25.

29. Naher S, Aziz MA, Akter I, et al. Analgesic, anti-inflammatory and antipyretic activities of methanolic extract of Cordyline fruticosa (L.) A. Chev. leaves. Journal of Research in Pharmacy. 2019;23:198-207.

30. Pantzar M, Ljungh A, Wadström T. Plasminogen binding and activation at the surface of Helicobacter pylori CCUG 17874. Infect Immun. 1998;66(10):4976-4980.

31. Ansari P, Uddin MJ, Rahman MM, Anti-inflammatory, anti-diarrheal, thrombolytic and cytotoxic activities of an ornamental medicinal plant: Persicaria orientalis. J Basic Clin Physiol Pharmacol. 2017;28(1):51-58.

32. Ali MS, Amin MR, Kamal CM, et al. In vitro antioxidant, cytotoxic, thrombolytic activities and phytochemical evaluation of methanol extract of the A. philippense L leaves. Asian Pac J Trop Biomed. 2013;3(6):464 469.

33. Wang H, Lottenberg R, Boyle MD. Analysis of the interaction of group a streptococci with fibrinogen, streptokinase and plasminogen. Microb Pathog. 1995;18(3):153-166.

34. Sikri N, Bardia A. A history of streptokinase use in acute myocardial infarction. Tex Heart Inst J. 2007;34(3):318-327.

35. Sokeng SD, Koubé J, Dongmo F, et al. Acute and chronic antiinflammatory effects of the aqueous extract of Acacia nilotica (L.) Del. (Fabaceae) pods. Academia Journal of Medicinal Plants. 2013;1(1):1-5.

36. Carlson RP, O’Neill-Davis L, Chang J, et al. Modulation of mouse ear edema by cyclooxygenase and lipoxygenase inhibitors and other pharmacologic agents. Agents Actions. 1985;17(2):197-204.

37. Kodithuwakku ND, Pan M, Zhu YL, et al. Anti-inflammatory and antinociceptive effects of Chinese medicine SQ gout capsules and its modulation of pro-inflammatory cytokines focusing on gout arthritis. $J$ Ethnopharmacol. 2013;150(3):1071-1079.

38. Sowemimo A, Onakoya M, Fageyinbo MS, et al. Studies on the anti-inflammatory and anti-nociceptive properties of Blepharis maderaspatensis leaves. Revista Brasileira de Farmacognosia. 2013;23(5):830-835.

39. Vogel HG. Drug discovery and evaluation: pharmacological assays. Springer Science \& Business Media.

40. Tang L, Eaton JW. Inflammatory responses to biomaterials. Am J Clin Pathol. 1995;103(4):466-471.

41. Pingsusaen $\mathrm{P}$, Kunanusorn $\mathrm{P}$, Khonsung $\mathrm{P}$, et al. Investigation of antiinflammatory, antinociceptive and antipyretic activities of Stahlianthus involucratus rhizome ethanol extract. J Ethnopharmacol. 2015;162:199206. 